\title{
Recurrent Childhood Grade III Lymphomatoid Granulomatosis
}

National Cancer Institute

\section{Source}

National Cancer Institute. Recurrent Childhood Grade III Lymphomatoid Granulomatosis. NCl Thesaurus. Code C115367.

The reemergence of grade III lymphomatoid granulomatosis in childhood after a period of remission. 